\title{
INCORPORATING THREE-DIMENSIONAL BAROCLINIC PROCESSES FOR ACCURATE DEPTH-INTEGRATED COASTAL CIRCULATION MODELLING
}

\author{
William Pringle, University of Notre Dame, wpringle@nd.edu \\ Joannes Westerink, University of Notre Dame, jjw@ nd.edu
}

\begin{abstract}
Depth-integrated coastal circulation models have proven to provide high-fidelity solutions to storm surge, tides, tsunamis, and those with wave-coupling (Westerink et al. 2008; Titov \& Synolakis 1998). They are able to provide high horizontal resolution, and stable, high-order and low-diffusion numerical schemes making them often more useful than their threedimensional counterparts despite more assumptions on the physics. However, the assumptions of no baroclinicity means that some processes such as steric effects, barotropic energy to baroclinic tidal energy conversion, and major baroclinic current systems cannot be directly modelled, creating limitations. This is directly problematic for example in storm surge forecasting systems where an offset between measured and predicted hydrographs (see Figure 1) may be present due to seasonal heating and cooling, changes to nearshore stratification and to the transport rates of major current systems and fresh water outflows.
\end{abstract}

This study presents a process coupling paradigm to incorporate three-dimensional baroclinic effects into a depth-integrated model from a widely used and available baroclinic model, HYCOM (http://hycom.org). The depth-integrated finite-element model, ADCIRC (Westerink et al. 1992) is able to provide highresolution to the coastal area, and has proven to be extremely accurate for storm surge modelling in e.g. the Gulf of Mexico (Westerink et al. 2008). However, along the Gulf of Mexico and east-coast of USA there are noticeable seasonal and inter-annual trends in the coastal sea level making forecasting more challenging than hindcasting (Figure 1). We present the effects of applying the information provided by HYCOM to ADCIRC in order to improve predicted hydrographs throughout the year of 2012 and in particular during Hurricane Sandy.

ADCIRC solves the depth-integrated shallow water equations. The following sink-like terms in the momentum equations are introduced when baroclinic effects are considered:

$$
\begin{gathered}
\nabla B=\int_{-h}^{\zeta}\left(g \nabla\left[\int_{z}^{\zeta} \frac{\left(\rho-\rho_{0}\right)}{\rho_{0}} d z\right]\right) d z \\
\mathrm{~F}_{i t}=C_{i t} \frac{\left[\left(N_{b}^{2}-\omega^{2}\right)\left(\widetilde{N^{2}}-\omega^{2}\right)\right]^{1 / 2}}{\omega}(\nabla h \cdot \boldsymbol{u}) \nabla h
\end{gathered}
$$

where $\nabla B$ is the depth-integrated baroclinic pressure gradient, $\zeta$ is the free surface, $h$ is the undistributed water depth, $\rho$ is the density, $\rho_{0}$ is the reference density of water, $g$ is the gravitational acceleration, $\mathrm{F}_{i t}$ is the barotropic to baroclinic energy conversion due to internal tides, $C_{i t}$ is a dimensionless tuning parameter approximately equal to $0.2, N_{b}$ is the buoyancy frequency at the seabed, $\widetilde{N}$ is the depth-averaged buoyancy frequency, $\omega$ is the pertinent tidal frequency (usually of the $\mathbf{M}_{2}$ tidal wave), and $\boldsymbol{u}$ is the depth-averaged velocity vector.

To get the necessary baroclinic terms the following steps are taken: 1) interpolate the conservative temperature and absolute salinity field from a 3D baroclinic model such as HYCOM onto the ADCIRC grid at every depth layer that is provided in the HYCOM output, 2) compute the density field on the ADCIRC grid using typical equations of state, 3) compute the buoyancy frequencies $N_{b}$ and $\widetilde{N}$ at each ADCIRC grid point based on the density field for use in $\mathrm{F}_{i t}$, 4) numerically evaluate the integral and gradients of the density field at each ADCIRC grid point to get $\nabla B$.

The concept of this approach is the similar to mode-splitting in 3D ocean models (which HYCOM itself does). However, in the current approach the horizontal grid and numerical model is completely separate. It is acknowledged that difficulties may arise in nearshore estuarine regions where the densities from the coarse grid HYCOM model may in fact be extrapolated from further offshore (here nearest neighbor extrapolation is used). This could be improved by trying to use local 3D ocean models if they are available in the region of interest, e.g. NYHOPS in the New York harbor region (Blumberg et al. 1999).
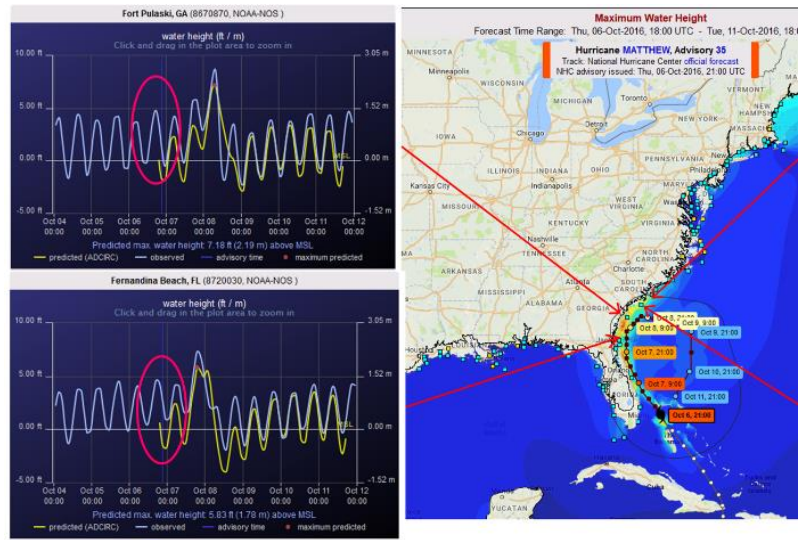

Figure 1 - Initial offsets between measured and predicted hydrographs for hurricane Matthew due baroclinic effects that are usually ignored by the ADCIRC model. ADCIRC forecasts can be obtained from http://nc-cera.renci.org/

\section{REFERENCES}

Blumberg, A. F., L. A. Khan, and J. P. St. John, 1999. Three-Dimensional Hydrodynamic Model of New York Harbor Region. Journal of Hydraulic Engineering, 125(8), 799-816.

Titov, V. V. \& Synolakis, C.E., 1998. Numerical Modeling of Tidal Wave Runup. Journal of Waterway, Port, Coastal, and Ocean Engineering, 124(4), pp.157-171.

Westerink, J.J. et al., 2008. A Basin- to Channel-Scale Unstructured Grid Hurricane Storm Surge Model Applied to Southern Louisiana. Monthly Weather Review, 136(3)

Westerink, J.J. et al., 1992. Tide and Storm Surge Predictions Using Finite Element Model. Journal of Hydraulic Engineering, 118(10), pp.1373-1390. 